\title{
ANTIBIOTIC RESISTANCE OF GROUP B STREPTOCOCCUS IN PREGNANT WOMEN AT 35-37 WEEKS OF GESTATION IN SOUTHERN VIETNAM
}

\author{
Thi Nhu Le TRAN ${ }^{1,2}$, Thi Diem Kieu PHAM ${ }^{3}$, Thi Gai LE ${ }^{1}$, Thi My Tien LE ${ }^{1,4}$, Ngoc Niem BUl${ }^{1}$, \\ Van De TRAN ${ }^{1^{*}} \square$, Kieu Anh Tho Pham ${ }^{1}$, Truong Khanh LIEU ${ }^{5}$, Xuan Sam AU ${ }^{1}$, \\ Kim Nguyen LE ${ }^{1}$, Rebecca S. DEWEY', Van Truyen NGO ${ }^{1,2}$ \\ ${ }^{1}$ Can Tho University of Medicine and Pharmacy, Can Tho city, Vietnam \\ ${ }^{2}$ Can Tho University of Medicine and Pharmacy Hospital, Can Tho city, Vietnam \\ ${ }^{3}$ Long An General Hosptial, Can Tho city, Vietnam \\ ${ }^{4}$ Can Tho Rehabilitation Hospital, Can Tho city, Vietnam \\ ${ }^{5}$ Can Tho Central General Hosptial, Can Tho city, Vietnam \\ ${ }^{6}$ University of Nottingham, Nottingham, United Kingdom
}

\section{Abstract}

Introduction. Group B Streptococcus (GBS) is the most frequent cause of early onset neonatal sepsis.

The objective of the study was to assess antibiotic resistance of GBS in pregnant women at 35-37 weeks of gestation in South Vietnam.

Materials and methods. A descriptive cross-sectional study was conducted between April 2018 and May 2019 in Can Tho University of Medicine and Pharmacy Hospital and Can Tho Maternity Hospital (Vietnam) to determine the incidence of GBS infection. Anorectal and vaginal samples were taken from 203 pregnant women attending an antenatal examination at 35-37 weeks of gestation. Specimens showing a positive result for GBS were evaluated to identify antibiotic resistance using the Kirby-Bauer test.

Results. The positive GBS rate in pregnant women was $16.3 \%$. The rate of antibiotic resistance in

\section{Résumé}

Résistance aux antibiotiques du streptocoque du groupe $\mathrm{B}$ chez les femmes enceintes à 35-37 semaines de gestation dans le sud du Vietnam

Introduction. Le streptocoque du groupe B (SGB) est la cause la plus fréquente de sepsis néonatal précoce.

L'objectif de l'étude était d'évaluer la résistance aux antibiotiques du SGB chez les femmes enceintes à 35-37 semaines de gestation au Sud Vietnam.

Matériaux et méthodes. Une étude transversale descriptive a été menée entre avril 2018 et mai 2019 à l'Hôpital Can Tho de l'Université de médecine et de pharmacie et à la maternité de Can Tho (Vietnam) pour déterminer l'incidence de l'infection à SGB. Des échantillons anorectaux et vaginaux ont été prélevés sur 203 femmes enceintes ayant subi un examen prénatal à 35-37 semaines de gestation. Les échantillons 
the GBS-positive samples analysed was as follows: Vancomycin (resistant 18.2\%, sensitive $81.8 \%$ ), Cefazolin (resistant 30.3\%, sensitive 69.7\%), Erythromycin (resistant 24.2\%, intermediate 9.1\%, sensitive 63.7\%), Clindamycin (resistant 63.7\%, intermediate $3 \%$ and sensitive 33.3\%), and Ampicillin (resistant $87.9 \%$, sensitive 12.1\%). In Vietnam, antibiotic prophylaxis for infection prevention in pregnant women with positive GBS includes Cefazolin and Vancomycin.

Conclusions. Pregnant women should be tested for GBS infection, ideally between weeks 35 and 37 of pregnancy. During labour, antibiotics such as Cefazolin and Vancomycin are most effective for preventing infections.

Keywords: antibiotic resistance, Group B Streptococcus, pregnancy, Vietnam. montrant un résultat positif pour le SGB ont été évalués pour identifier la résistance aux antibiotiques à l'aide du test de Kirby-Bauer.

Résultats. Le taux de SGB positif chez les femmes enceintes était de 16,3\%. Le taux de résistance aux antibiotiques dans les échantillons positifs au SGB analysés était le suivant : Vancomycine (résistante $18,2 \%$, sensible 81,8\%), Céfazoline (résistante 30,3\%, sensible 69,7\%), Érythromycine (résistante 24,2\%, intermédiaire 9,1\%, sensible 63,7\%), la Clindamycine (résistante 63,7\%, intermédiaire 3\% et sensible 33,3\%) et l'ampicilline (résistante $87,9 \%$, sensible 12,1\%). Au Vietnam, la prophylaxie antibiotique pour la prévention des infections chez les femmes enceintes présentant un SGB positif comprend la Céfazoline et la Vancomycine.

Conclusion. Les femmes enceintes doivent subir un test de dépistage de l'infection à SGB, idéalement entre les semaines 35 et 37 de la grossesse. Pendant l'accouchement, les antibiotiques tels que la Céfazoline et la Vancomycine sont les plus efficaces pour prévenir les infections.

Mots-clés: résistance aux antibiotiques, streptocoque du groupe B, grossesse, Vietnam.

conducted in either public or private healthcare setting. In Vietnam, the rate of GBS infection has reportedly increased over time, and is dependent on geographical factors, with incidence rates of $4.4 \%$ to $30 \%$ being reported depending on the location and method of bacterial identification ${ }^{5}$.

Currently, in South Vietnam, no study has reported vaginal and rectal GBS infection rates in pregnant woman at 35-37 weeks of gestation. To obtain statistics on GBS incidence in pregnant woman in South Vietnam, as well as to establish recommendations for the administration of the correct type of preventive antibiotics, we conducted a study aiming to determine the antibiotic resistance of GBS isolated from anorectal and vaginal fluids of pregnant women at 35-37 weeks in South Vietnam. of appropriate antibiotics are very important to prevent GBS transmission from mother to infant. The Centers for Diseases Control and Prevention (CDC) recommended in 2010 that pregnant women must be investigated for GBS at 35-37 weeks of gestation and, if positive, they must be given preventive antibiotics to prevent early-onset neonatal sepsis. However, in Vietnam, there is no routine strategy of screening for vaginal or rectal GBS infection in pregnant women, and the prophylaxis for neonatal infection is rarely used. Large-scale research has not yet been
The OBJECTIVE OF THE STUDY was to determine the antibiotic resistance of GBS isolated in pregnant women and to recommend which antibiotics should be used for infection prevention at 35-37 weeks of gestation.

\section{Ethics statement}

This study was approved by the Research Ethics Committee of Can Tho University of Medicine and

\section{Materials AND Methods}


Table 1. The process of identifying the GBS-antimicrobial content of samples taken.

\begin{tabular}{ccl}
\hline Step 1 & First day & $\begin{array}{l}\text { Incubation of tube containing microbial growth medium and specimens at a temperature } \\
\text { of } 37^{\circ} \mathrm{C} \text { for } 18-24 \mathrm{~h} \text { inside a candle jar to achieve a } \mathrm{CO}_{2} \text { concentration of } 5-10 \% . \\
\text { Isolation of bacteria by } 3 \text {-dimensional implantation technique on blood agar medium. } \\
\text { Blood agar medium was continously incubated for } 18-24 \mathrm{~h} \text { at a temperature of } 37^{\circ} \mathrm{C} .\end{array}$ \\
\hline Step $2 \quad$ Second day & $\begin{array}{l}\text { Observe hemolysis phenomenon, select hemolysis } \beta \text { colonization and conduct gram stain, } \\
\text { observe gram-positive cocci mostly form a string arrangement. Those testing positive are } \\
\text { implanted on blood agar medium again in order to increase the number of bacteria, incu- } \\
\text { bated at a temperature of } 37^{\circ} \mathrm{C} \text { for } 18-24 \mathrm{~h}, 5-10 \% \mathrm{CO}_{2} \text { inside a candle jar. } \\
\text { Isolation and identification of } \mathrm{GBS} \text { using the CAMP-Test. }\end{array}$ \\
\hline Step 3 & Third day $\quad$ Antimicrobial susceptibility testing on blood agar.
\end{tabular}

Table 2. Rates of antibiotic sensitivity and resistance of GBS in the 33 participants who tested positive.

\begin{tabular}{|c|c|c|c|}
\hline & \multicolumn{3}{|c|}{ Antibiotic sensitivity and resistance } \\
\hline & Sensitive $(S)$ & Intermediate (I) & Resistant $(R)$ \\
\hline Ampicillin $10 \mu g$ & $12.1 \%$ & & $87.9 \%$ \\
\hline Erythromycin $15 \mu \mathrm{g}$ & $63.7 \%$ & $9.1 \%$ & $24.2 \%$ \\
\hline Cefazolin $10 \mu \mathrm{g}$ & $69.7 \%$ & & $30.3 \%$ \\
\hline Vancomycin $30 \mu g$ & $81.8 \%$ & & $18.2 \%$ \\
\hline Clindamycin $2 \mu g$ & $33.3 \%$ & $3 \%$ & $63.7 \%$ \\
\hline
\end{tabular}

Pharmacy Hospital and Can Tho Maternity Hospital, Vietnam (approval number 148A/HĐĐĐ-PCT, February 12, 2018). Pregnant women were approached and given the opportunity to voluntarily participate in the study, after the purpose of the study had been explained to them. All participants signed a written informed consent form prior to taking part in the study. All data were stored confidentially.

Study population

This study was carried out from April 2018 to May 2019 at Can Tho University of Medicine and Pharmacy Hospital and Can Tho Maternity Hospital, Vietnam. The inclusion criteria were (1) the women attending the hospital for a routine examination between the $35^{\text {th }}$ and $37^{\text {th }}$ week of gestation, (2) the women had not used a vaginal suppository or vaginal douche in the 48 hours before the examination, and (3) written informed consent to participate in the study. The exclusion criteria were (1) any patient who had previously participated in this study, or (2) treatment with systemic antibiotics in the two weeks before enrollment in the study.

\section{Sample collection and processing}

In total, 203 women were recruited for the study. Physical examination was performed and a vaginal-rectal swab was taken from each participant. Specimens were transferred to the microbiology laboratory of Can Tho Medical and Pharmaceutical University Hospital in the same day. The results of infection and antimicrobial resistance were available within 72 hours. The process of isolating and identifying GBS within the samples followed the procedure outlined in Table 1.

\section{Antibiotic resistance of GBS}

GBS antibiotic resistance levels were ascertained using an antimicrobial susceptibility testing technique with Ampicillin, Cefazolin, Vancomycin, Erythromycin, and Clindamycin. The criteria for evaluating antibiotic resistance to GBS were based on the 2014 Clinical and Laboratory Standards Institute (CLSI) table for identification ${ }^{6}$. Data were analysed using SPSS 18.0.

\section{Results}

\section{Patients' characteristics}

The mean age of participants $(n=203)$ was $28.3 \pm 5.101$ years (range 21 to 41 years); 134 participants lived in urban areas (66\%) and 69 lived in rural areas (34\%); 32 participants (15.7\%) had one risk factor in the obstetric history, such as premature birth, miscarriage or perinatal death, 19 (9.4\%) had more risk factors, and 152 women $(74.9 \%)$ had no risk factors.

\section{Sensitivity and antibiotic resistance}

There were 33 cases of positive vaginal or rectal GBS infection (16.3\%). Of these 33 cases, antibiotics were most susceptible to Vancomycin $(81.8 \%)$ and cefazolin $(69.7 \%)$, whereas $87.9 \%$ of the patients had strains resistant to Ampicillin (87.9\%) or clindamycin 
Table 3. Comparison of GBS infection rates between studies.

\begin{tabular}{cccc}
\hline Study & $\begin{array}{c}\text { Rate of GBS infection } \\
\text { (percentage) }\end{array}$ & Samples taken from & Study location \\
\hline $\begin{array}{c}\text { Goto A (2005) } \\
\text { John Kam-On Chung } \\
(2010)^{7}\end{array}$ & $4.0 \%$ & Vaginal fluid - rectum & North Vietnam \\
\hline $\begin{array}{c}\text { Müller-Vranjes A } \\
(2011)^{8}\end{array}$ & $14.6 \%$ & Urine - vaginal fluid & Hong Kong \\
\hline $\begin{array}{c}\text { Authors in Poland } \\
(2013)^{9}\end{array}$ & $24.6 \%$ & Vaginal fluid - rectum & Croatia \\
\hline Our study (2018) & $19 \%$ & Vaginal fluid - rectum & South Vietnam \\
\hline
\end{tabular}

(63.7\%). There were no cases of resistance to all five antibiotics simultaneously. The antibiotic sensitivity and resistance of the 33 patients who tested positive are presented in Table 2.

\section{Risk factors for GBS infection}

Participants who had both pruritus and dysuria showed a 4.0 times higher risk of testing positive for GBS than asymptomatic participants $(p<0.05)$ and a 6.6-times higher prevalence than participants with only one symptom $(p<0.05)$. Women living in urban areas had a 3.4 times higher rate of GBS infection than women from rural areas $(p<0.05)$. Participants with two or more antenatal factors (premature birth, miscarriage, perinatal death) had a 7-times higher risk of testing positive for GBS than women with only one risk factor $(p<0.05)$.

The rate of GBS infection is shown in Table 3.

\section{Discussion}

This study aims to replicate in South Vietnam what other studies have achieved elsewhere in the world in terms of describing the incidence of GBS in the vaginal-rectal fluids of pregnant women. For example, a study in the USA reported an incidence of GBS between 10 and 30\% ${ }^{10}$, another in Europe reported that between $6.5 \%$ and $36 \%$ of their participants tested positive ${ }^{11}$, and a study in Asia reported incidence rates of $7.1-16 \%{ }^{12}$. The incidence of vaginal rectal GBS reported in the present study $(16.3 \%)$ was considerably higher than that of previous studies with lower incidence rates, particularly one conducted in North Vietnam in $2005(4.0 \%)^{5}$ (Table 3). This sizeable difference may be due to the methodology of sample collection, as it only analysed vaginal samples, whereas the present study used vaginal and rectal samples. In addition, the GBS infection rate also varies geographically and with different levels of scientific and technical understanding, which itself varies significantly over time for a given region. Conversely, the GBS infection rate reported in the present study was lower than in other studies, such as that of Müller-Vranjes et al. ${ }^{8}$, carried out in 118 pregnant women in Croatia, who reported that $24.6 \%$ of their group of study was having a GBS infection. A similar study carried out in a larger sample of 273 women in Poland showed a GBS prevalence of $19 \%{ }^{9}$. However, the prevalence of GBS in this study was higher than that of a 2010 study conducted in Hong Kong ${ }^{13}$, reporting an incidence of vaginal and rectal GBS infection of $14.6 \%$. This difference is likely due to the lack of routine GBS screening in pregnant women in Vietnam in comparison to other countries, and as such the rate of detection of GBS through screening of vaginal and rectal fluid is not high.

A study by Nomura et al. ${ }^{14}$ suggested that the detection rate of GBS varied with the site from which the fluid sample was taken, for example varying from $20-40 \%$ at one site compared to $18-24 \%$ at another. They also reported that a more accurate detection rate can be obtained by taking samples from the labia, and that samples cultured in selective conditions had higher infection rates than those cultured in non-selective conditions ${ }^{14}$. Therefore, in order to accurately determine the GBS infection rate in pregnant women, for the purpose of preventing early neonatal infection, it is advised to culture specimens taken from both the vagina and rectum in a selective nutritional environment, as it has been conducted in the present study.

\section{GBS antibiotic resistance}

Our results showed that the antibiotic with the most prevalent sensitivity profile for GBS was Vancomycin (81.8\%), however the sensitivity of GBS to Vancomycin was lower than that reported previously $^{15}$. However, as Vancomycin is expensive in comparison to other antibiotics, it is not used as a first-line treatment, and is not typically considered for treatment of pregnant women with a GBS infection. GBS showed the second highest rate of sensitivity to antibiotics in the cephalosporine group (Cefazolin), 
with $69.7 \%$ of positive cases showing sensitivity to cephalosporines. However, the sensitivity of GBS to the cephalosporine group in the present study was lower than that reported previously ${ }^{15,16}$. The third highest rate of antibiotic sensitivity was to eerythromycins, with $66.7 \%$, of positive GBS cases showing sensitivity. Previous reports show that erythromycin sensitivity varies greatly with region, ranging from very low levels of sensitivity (17\%) to $91.66 \%{ }^{15}$.

The CDC and World Health Organization recommend either Penicillin or Ampicillin as first-line antibiotics in the prevention of GBS infection in newborns, but the resistance of GBS to these two antibiotics was very high, up to $87.9 \%$, with Ampicillin being the most-resisted antibiotic among the five antibiotic groups included in the present study. Previous studies have demonstrated significant regional variations in the antibiotic resistance of GBS, and this is also the case with Ampicillin. However, on the basis ground of the present findings, we strongly recommend avoiding the use of ampicillin for GBS prophylaxis in South Vietnam.

The Clindamycin resistance of GBS was also quite high, $63.7 \%$, with only $33.3 \%$ of positive cases showing sensitivity and 3\% intermediate sensitivity, again with a lower sensitivity than that reported previously in Bulgaria, for example $(91.66 \%)^{15}$.

In summary, the rate of GBS antibiotic resistance in our study was high for Ampicillin and Clindamycin. The highest levels of sensitivity were found for Vancomycin, followed by Cefazolin, and Erythromycin. Based on our findings, we recommend that Ampicillin and Clindamycin should not be used as first-line antibiotics for the prevention of neonatal sepsis in Can Tho region. Conversely, we do recommend the use of Cefazolin for prophylactic treatment, due to its reasonable price and due to GBS showing a relatively high sensitivity to it. The greatest number of positive GBS cases showed sensitivity to Vancomycin, but it is costly and it is not used as a routine option. Erythromycin can also be considered for GBS prophylaxis, but with the caveat that Erythromycin has been reported to have cross-resistance to Clindamycin, having the same mechanism of action and a similar chemical structure, and GBS was found to be highly resistant (63.7\%) to Clindamycin.

Studies have obtained differences in their findings of antibiotic resistance rates between countries, due to the characteristics of antibiotic use that vary with region and country. In Vietnam, the use of antibiotics is widespread and people can buy antibiotics without a prescription, a practice especially common in rural areas. In Can Tho, the long-term overuse of Ampicillin to treat infections may have increased the resistance of bacteria (including GBS) to antibiotics. There has not been a recent study of GBS antibiotic resistance conducted in the Southern region of Vietnam. Monitoring of antibiotic resistance rates for GBS and other bacterial infections is recommended on a regional and per-hospital basis, to inform the appropriate antibiotic treatment selection for each site.

\section{Limitations}

The study only focused on two hospitals in Can Tho city, so the antibiotic resistance in the region has not been fully mapped. The identification of GBS was carried out using conventional methods of culture identification, and the sensitivity provided by this study may be lower than that obtained by using polymerase chain reaction (PCR). Future studies should monitor the efficacy of antibiotic prophylaxis for neonatal infections in pregnant women with positive GBS results. Antibiotic selection should be based on local and recent knowledge of antimicrobial resistance. If no recent and local antibiotic resistance testing has been conducted, antibiotics should be selected in the following order: Cefazolin, followed by Vancomycin, and finally Erythromycin. It is recommended to screen for GBS infection in newborns whose mothers tested positive for GBS and who have not received antenatal prophylactic antibiotic therapy.

\section{Conclusions}

The prevalence of GBS infection in pregnant women is high, therefore screening is required for the early detection, prevention, treatment, and control of the infection. Vancomycin and Cefazolin are two effective antibiotics for the treatment of GBS infection in pregnant women at 35-37 weeks of gestation in Southern Vietnam. Women with symptoms of pruritus and dysuria, living in urban areas, and pregnant women with at least two previous risk factors (premature birth, miscarriage, perinatal death) should be monitored for infection with GBS.

\section{Author Contributions:}

Conceptualization, T.N.L.T. and T.D.K.P.; methodology, T.N.L.T. and N.N.B.; software, T.N.L.T. and T.G.L.; validation, T.D.K.P. and T.G.L.; formal analysis, T.D.K.P. and K.A.T.P.; investigation, T.N.L.T.; resources, T.D.K.P. and K.N.L.; data curation, T.G.L. and N.N.B.; writingoriginal draft preparation, T.N.L.T. and T.G.L.; writing-review and editing, N.N.B., V.D.T., K.A.T.P., X.S.A. R.S.D; visualization, V.D.T. and T.K.L.; supervision, T.K.L and V.T.N..; project administration, V.T.N. All the authors have read and agreed with the final version of the article. 


\section{Compliance with Ethics Requirements:}

The authors declare no conflict of interest regarding this article. The authors declare that all the procedures and experiments of this study respect the ethical standards in the Helsinki Declaration of 1975, as revised in 2008(5), as well as the national law. Informed consent was obtained from all the patients included in the study. There are no funding sources to declare for this study.

\section{Acknowledgements}

The authors are grateful to the members of department of Can Tho University of Medicine and Pharmacy in Vietnam.

\section{References}

1. Couturier BA, Weight T, Elmer H, Schlaberg R. Antepartum screening for group B Streptococcus by three FDA-cleared molecular tests and effect of shortened enrichment culture on molecular detection rates. Journal of Clinical Microbiology. 2014;52(9):3429-32.

2. Ferrieri P, Lynfield R, Creti R, Flores AE. Serotype IV and invasive group B Streptococcus disease in neonates, Minnesota, USA, 2000-2010. Emerging Infectious Diseases. 2013;19(4):551-8.

3. Mitchell A, Steffenson N, Hogan H, Brooks S. Group B streptococcus and pregnancy: update and recommendations. The American Journal of Maternal Child Nursing. 1997;22(5):242-8.

4. Castor ML, Whitney CG, Como-Sabetti K, et al. Antibiotic resistance patterns in invasive group B streptococcal isolates. Infectious Diseases in Obstetrics and Gynecology. 2008;2008:727505.

5. Goto A, Nguyen QV, Pham NM, et al. Prevalence of and factors associated with reproductive tract infections among pregnant women in ten communes in Nghe An Province, Vietnam. Journal of Epidemiology. 2005;15(5):163-72.

6. Clinical and Laboratory Standards Institute. Performance Standards for Antimicrobial Susceptibility Testing; Twenty-Third Informational Supplement. 2014:M100-S23, 33.
7. Chung JKO, Ling TKW, Tam DCC. The prevalence of group B streptococcus colonization in pregnant women in Hong Kong. Journal of Hong Kong Institute of Medical Laboratory Sciences. 2012; 13(1,2):1-16.

8. Muller-Vranjes A, Puntaric D, Curzik D, et al. Prevalence and significance of vaginal group B streptococcus colonization in pregnant women from Osijek, Croatia. Collegium Antropologicum. 2011;35(1):21-6.

9. Brzychczy-Wloch M, Wojkowska-Mach J, Helwich E, Heczko PB. Incidence of maternal GBS colonization and neonatal GBS disease among very low birth weight Polish neonates. Med Sci Monit. 2013;19:34-39.

10. Schuchat A. Epidemiology of group B streptococcal disease in the United States: shifting paradigms. Clinical Microbiology Reviews. 1998;11(3):497-513.

11. Barcaite E, Bartusevicius A, Tameliene R, Kliucinskas M, Maleckiene L, Nadisauskiene R. Prevalence of maternal group B streptococcal colonisation in European countries. Acta Obstetricia et Gynecologica Scandinavica. 2008;87(3):260-71.

12. Ippolito DL, James WA, Tinnemore D, et al. Group B streptococcus serotype prevalence in reproductive-age women at a tertiary care military medical center relative to global serotype distribution. BMC Infectious Diseases. 2010;10:336.

13. Chung JKO, Ling TKW, Tam DCC. The prevalence of group B streptococcus colonization in pregnant women in Hong Kong. Journal of Hong Kong Institute of Medical Laboratory Sciences. 2012;13(1,2):1-16.

14. Nomura ML, Junior RP, Oliveira UM. Selective versus non-selective culture medium for group B Streptococcus detection in pregnancies complicated by preterm labor or preterm-premature rupture of membrances. Braz J Infect Dis. 2006;10(4):490-495.

15. Decheva A, Zlatkov V, Pandev K, et al. Screening study on pregnant women and neonatal infection with Streptococcus agalactiae (Group B Streptococci). Akush Ginekol (Sofiia).2013;52(7):4-7.

16. Dutra VG, Alves VM, Olendzki AN, et al. Streptococcus agalactiae in Brazil: serotype distribution, virulence determinants and antimicrobial susceptibility. BMC Infect Dis. 2014;14:323.

17. Yeung SW, Sahota DS, Leung TY, et al. Comparison of the effect of penicillins versus erythromycin in preventing neonatal group B Streptococcus infection in active carriers following preterm prelabor rupture of membranes. Taiwan J Obstet Gynecol. 2014;53(2): 210-4. 